\title{
Information Behavior of Mothers during Pandemics: The Case of COVID-19
}

\author{
Asma Alwreikat ${ }^{1 *}$ \\ Library and information management Dept. Al-Salt college for human sciences , \\ Al-Balqa Applied University, Al-Salt 19117 PoBox 206 Jordan
}

\begin{abstract}
The study aims to investigate information behavior of pupils' mothers during COVID-19 pandemic. The study deployed a qualitative approach using semi-structured interviews. The sample of the study consisted of 24 mothers. The data analysis revealed three major themes of mothers' information behavior; these are information needs, exploration and monitoring. The results of this study identifies several implications. First it bridged the gap between theories of information behavior and the various models available and practice of information behavior during pand,emics, particularly mothers' behavior. The study presented suggestions to policymakers and governments in aiding mothers with appropriate support they need in the context of pandemics and public health emergencies.
\end{abstract}

Keywords: Information behavior, Mothers information behavior, Information seeking, Exploration, Information needs, Monitoring, COVID-19

DOI: $10.7176 / \mathrm{IKM} / 12-1-02$

Publication date: January $31^{\text {st }} 2022$

\section{Introduction}

Rapid developments of online sources has changed the way people seek and obtain information. In the last two decades health information has been widely disseminated via online sources, as a consequence seeking information through online sources has become in popularity. Health information seeking has been considered as "a key coping strategy in health-promotive activities and psychosocial adjustment to illness" (Lambert SD, 2007, p.1006). Numerous studies have reported that more women were searching health information online than men (Renahy \& Chauvin, 2006)

Seeking health information using the internet is increasingly becoming acceptable, as health organizations keep posting and uploading health information for people on the internet. The outbreak of COVID-19 (known as Coronavirus) considers one of the health issues that people seek information to deal with in a proper way. COVID19 is an acute respiratory disease caused by a newly emerged zoonotic coronavirus (Domanović, 2020). COVID19 considers highly contagious, and it affects community's movement and every day social life, and on the time of its outbreak in the first quarter of the 2020 it was considered as a mysterious dieses. Mothers with pupils were put under huge pressure for taking percussion measures to protect their children while in schools. This research aims to investigate the information behaviour of mothers of pupils in regards COVID-19 outbreak by using a qualitative approach.

1.1 Background on COVID 19

News in 31 December 2019 started coming from China reporting a spread of a mysterious disease similar to the Severe Acute Respiratory Syndrome (SARS) which was recognized at the end of February 2003. The disease was identified as novel coronavirus. A cluster of patients with the disease was identified in the city of Wuhan, China. The virus was named initially tentatively 2019 novel coronavirus (2019-nCoV), the virus has now been named SARS-CoV-2 by the International Committee of Taxonomy of Viruses (ICTV) (WHO, 2020). The outbreak of the virus in China and its vast spread outside China caused a significant global panic, and caused a worldwide run on facemasks and countries to lockdown megacities, ban traveling and shut schools (Molteni, 2020). On 11 March 2020, the WHO declared the COVID-19 outbreak a pandemic. Until the time of writing this research the COVID 19 still has no registered medicine and still taking thousands of lives every day. The misinformation on COVID 19 via social media has had a significant impact on popular anxiety surrounding this outbreak (Nawrat, 2020)

\section{Literature review}

\subsection{Information behaviour}

Three different concepts appeared in the literature, Information Behaviour (IB), Information Seeking Behaviour (ISB) and Information Searching (IS). Wilson, who originally coined the term IB defined it as "the totality of human behaviour in relation to sources and channels of information, including both active and passive information seeking, and information use." (Wilson, 2000, 49). IB appears as the broadest level, and IS appears as the most focused. ISB is a subset of IB field. Case, (2007) presented a definition which resembles an earlier definition by Krikelas (1983) who states that ISB is the activities that an individual undertakes to satisfy a perceived need (p.6). Case's definition subsumed previous definitions and focused on the process of seeking and the actions a person 
may take to satisfy a goal rather than focusing on the needs.

IS is the micro' level of behaviour employed by the searcher in interacting with information systems (Wilson, 2000 , p. I). The literature of IB does not only involve the act of searching information, it also incorporates the area of cognitive style and individual differences, feelings, thoughts, uncertainty and serendipity (Kuhlthau, 1993;Wilson, 1999;Vakkari, 1999; Ellis, 1987; Ellis et al., 1993; Sonnenwald, 1999). The development of theoretical models attracted the attention of many researchers such as (Ellis, 1987; Ellis, 1989; Ellis and Haugan, 1997; Kuhlthau, 1993; Kuhlthau, 2004; Wilson, 1981; Wilson and Walsh, 1996; Dervin, 1983; Foster, 2003, 2004;2006; Foster and Urquhart, 2012). Models are useful in identifying and depicting IB of users in general or of specific users.

\subsection{Health Information behaviour under pandemics}

According to Fox (2011) health information is one of the most important subjects users search online, with symptoms and treatment dominating this online search. Health information is defined here as any information related to a person's medical history, diagnoses, symptoms and procedures (AHIMA, 2019). Renahy \& Chauvin (2006) found that users perceived the internet as a fast and a reliable tool for obtaining health information, comparing information from different websites, and looking for sensitive topics with a complete privacy. According to Martinović (2016) parents' of children diagnosed with illnesses first reaction would be seeking information from different sources to better understand the illness and enhance their knowledge about their child's illness. Wilson and Walsh (1996) subdivide health information needs into two categories: cognitive needs (obtaining more factual information about disease prevention, detection and/or treatment) or affective needs (obtaining information which is expected to provide aid in dealing with the disease emotionally).

Several studies focused on information behavior of mothers in different contexts, nevertheless, all these studies mentioned health as one of the topics that mothers seek information about. (Landry, 2007), but studies on mothers information behavior during pandemics was limited.

\section{Research Questions}

This study will answer the following research questions:

Q1 What is the information behavior of mothers of pupils when collecting information on COVID 19 outbreak?

Q2 What are the sources mothers used in collecting such information?

Q3 What feelings effect mothers information behavior?

\section{Methodology}

In order to answer the research questions the researcher used a qualitative approach using semi-structured interviews. Semi-structured interviews are thought to give an insight into information behavior, they are most useful in the case of this research project because the researcher is seeking answers for specific questions to meet the research aims, and they enable to achieve a better understanding of information behavior of mothers during pandemics. Wilson (1981) supports the use of qualitative approach in studying information behavior (p.7). Quantitative methods would not be able to investigating the information behavior of mothers. The interviews were conducted to explore information needs of mothers during pandemics, feelings, sources of information and seeking behavior. An interview guide was used to keep the interviews focused on the aim of the research, however the researcher remained flexible in asking broad to encourage participants to speak about their information behavior in detail. Following the data collection from the interviews, all interviews were transcribed and analyzed using thematic analysis. Thematic analysis is "identifying, analyzing and reporting patterns (themes) within data. It minimally organizes and describes your data set in (rich) detail. However, frequently it goes further than this, and interprets various aspects of the research topic" (Braun and Clarke2006.p. 6)

Ethical considerations were met, informed consent was obtained from participants before starting interviews, confidentiality, and anonymity were assured. Participation was on a voluntary basis. The researcher explained to each participant that they could withdraw at any point in the interview.

\subsection{Study sample}

The sample of the study consisted of 24 mothers of elementary children school (see figure 1 for sample demographics), the sample was purposively chosen from a local school in Al-Salt city in Jordan. 55 mothers were contacted, but only 26 mothers were willing to undertake interviews, at the time of the interviews two participants were not reachable, only 24 participants were interviewed. Four of the interviews were conducted in participants' houses. The twenty remaining interviews were conducted via Messenger, Viber and What's app video service using voice recording service available on mobile or laptop to make sure collected data is securely saved. Switching to video interviews were due to the nationwide curfew that was announced by the Jordanian government on 21 March 2020. The interviews questions aimed to explore the information behavior of mothers during pandemics and their feelings. 
Table 1: Demographics of the sample

\begin{tabular}{|c|c|c|}
\hline No & Age range & education \\
\hline 1 & $20-25(2)$ & High school (1) \\
\hline 2 & $26-30(6)$ & Diploma (5) \\
\hline 3 & $30-40(11)$ & Bachelor degree (15) \\
\hline 4 & $41-50(5)$ & Post graduate (3) \\
\hline
\end{tabular}

\section{Data analysis}

All interviews were tape recorded and transcribed and notes were taken during interviews to record any contextual information, the data were analyzed using thematic analysis approach, NVIVO software was used, the data were coded using open coding by coding almost all data provided from participants, then at the second stage the data were re-coded again using axial coding to narrow down and focus codes. Then, finally relationships among codes were derived to become more focused and storytelling by using selective coding and themes were generated. The saturation was reached after analyzing data of participant 18 , however, the researcher continued data analysis until participant 24 . The data analysis revealed the following themes:

\subsection{Information needs}

Information needs of the participants are explanatory constructs that help in understanding their information behavior. The developments around the disease caused changes in the information need of mothers. The first month of declaring infection cases in Jordan, mothers' information needs were toward bridging the gap about this disease in order to make sense of their life situation. This behavior was reflected by seeking information about the virus, knowing what it does, its symptoms and any possible medication.

"I really had no clue about the virus, what is its symptoms, how it spreads, and whether it is an animal transmitted virus! I just had lack of information at the beginning, my main focus was to seek answers to these questions. I was worried because I have a cat in the house and my children play with her all the time" P3

"we never had such case in Jordan. It took me few days to understand what is happening. It was a virus that originated in China that was the information I had. But when we started to register cases of infection, I felt that I need to know more information, particularly how it transmit and whether it is a fatal virus. At the beginning of its spread schools were open, and children were at high risk to catch infection, and that made me seek information on the precautions" P15

However, the data revealed that in terms of information needs the information behavior of mothers has changed after weeks of quarantine and more exposure to information about the virus. The more participants seek information, the more uncertainty and anxiety decrease and this makes their information needs more precise.

"The first few weeks when the government declared the Coronavirus as a pandemic was completely a strange situation for me, I've never been through such times. I was not sure what information I should look for, didn't have any idea about symptoms or medication. But few weeks later things was much clearer for me though the dieses is vague" P15

Another factor affected mothers information needs was changes happened to the context around them. According to mothers, these changes in their information needs was attributed to the decision of shutting down schools in the country and switching to e-learning. The anxiety and fear about children getting infected by the virus (see section on anxiety) was reduced now. Their information needs shifted towards following updates on the epidemiological situation. Previous literature supported these results and showed changes in information needs during public health emergences (Alwreikat, Shehata, \& Eldakkar, 2021) and (Sharifirad et al., 2014).

\subsubsection{Changes to information needs}

Weeks after the lockdown the information needs of participants were shifted from reading lengthy information on the disease to the need to a quick and fast information sources. According to participants this is due to being exposed to too much information at the first weeks of the virus spread.

" few weeks later I stopped reading articles from the newspaper or news pages, I just follow posts on Facebook and I even don't click on any links, I just read the headlines" P8

"...It is too much information, I just hear the daily press conference to know the numbers of registered cases or any deaths" P11

\subsection{Exploration}

In seeking information on Covid-19, mothers do not seek information in specialized websites or sources. The main source of information for mothers was Facebook posts and pages they follow on Facebook. All mothers mentioned that they did not seek information on ministry of health website.

"I only look on Facebook and scroll down looking for updates, its epidemic virus and everyone is busy in posting latest update on it" P6

Using Facebook as an information source on the virus for mothers included information on both facts on the 
virus and precautions, and at the same time, false information and rumors about the virus.

"I go through Facebook, sometimes I find useful information on how to wash hands in a proper way to prevent the infection, but at the same time, many information I read on the virus turned out later to be wrong" P2 1

Surprisingly, the data analysis revealed that participants do not go through the process of choosing the information source from various sources, they showed heavy dependence on Facebook. This result could be explained as the virus considers new and no enough information is out there on it. This result is opposite to results of many studies and research of information seeking. Example of study (Ellis, 1993); (Ford, 2015) (PierreChauvin, 2006); (Alwrekat et al., 2015)

This result may reflect dependency of participants on Facebook as a source of information. A study by (Bene, 2017; Alwreikat et al., 2021) came to support this result

On the other hand, all participants, mentioned they follow the daily report of ministry of health on national TV channels. To follow daily numbers on the spread of the virus.

"... every day at 8:00pm sharp, I turn the TV on to hear the daily report by the minister of health on the new number of reported cases" $\mathrm{P} 24$

\subsubsection{Avoidance}

As part of the exploration process, participants mentioned that while exploring information on the virus they would avoid or ignore reading some information that may cause them to have negative feelings or increase their fears of the virus. However, this behavior was reported while seeking information on the virus but it is not considered as seeking behavior but it is part of their information behavior.

One participant mentioned the term avoidance:

"I keep an eye on the news, to make sure that I'm informed about the virus, but sometimes I come across information about new variance that does not respond with medications, I really ignore reading on such news, it just causes me fear and frustration, I don't want to feel hopeless, specially the children started to go to school now and they socials with many other students, if I leave myself to such negative news I would stop sending them to school and switch again to online learning" P7

Another participant explained that keep following negative news causes bad feelings.

"Avoiding such news is the best thing that I could do myself and my children" P9

The analysis of the interviews revealed that avoiding is a behavior mothers practice, and it is related to avoiding any inconvenient and bad feelings such information may cause.

\subsection{Monitoring}

Opposite to avoiding, mothers showed the behavior of monitoring by following up-dates on the spread of the virus. Monitoring information on the virus is suggested to enhance coping by helping mothers understand the health threat and the associated challenges that it brings. The behavior of monitoring was very obvious as mothers showed feelings of fear and anticipation as it is health threatening situation.

As a pandemic, monitoring was very obvious with all participants' information behavior. Feelings of anxiety and uncertainty controlled user's behavior in seeking for information.

" ... whenever I wake up in the morning I grab my mobile and check my Facebook to see if there are any updates on the diesis and its spread, and any announcement on a vaccine" P2

"I keep an eye on any information on medication for the diesis or even a vaccine. The fact that there is no medication or a vaccine for the diesis just freaks me out, and I feel worried about my children"P14

Monitoring in this research associated with feelings of anxiety, uncertainty and anticipation due to the perceived severity of the situation. Almost all mothers mentioned that they follow news closely on the virus, in a way to control feelings of uncertainty and anxiety.

\subsection{Feelings}

The data analysis showed a range of feelings associated with the information seeking behavior of mothers, nevertheless, all these feelings found to be negative feeling, such as uncertainty and anxiety.

\subsubsection{Uncertainty}

The data analysis revealed feelings of uncertainty. The nature of the virus as being new and mysterious caused participants to seek information to find answers to calm down their fears. As one of the participants mentioned "I seek information hoping to find answers, but unfortunately the situation is vague and unclear" P7

" the first two weeks of the quarantine things were new to us, I was not sure what to look for, then more sources and information started come up, but however every day we read about new information that contradict existing information and makes any person to be uncertain what to follow" P9

Uncertainty also likely promotes learning about the virus, in part through information gathering about the disease. For example participant 18 adds

"being uncertain what to look for and what is that big beast attacking the world, prompts me to start reading about it. I feel I need to know my enemy”, 


\subsubsection{Anxiety}

As a health threatening situation, participants showed feelings of anxiety when talking about their information seeking on the disease.

"I'm sad, scared and worried. Worried about my kids, worried about my family, my own health, and my community" P5

Anxiety appeared when participants talked about seeking information on the virus to reduce feelings of fear and anxiety and to provide reassurance.
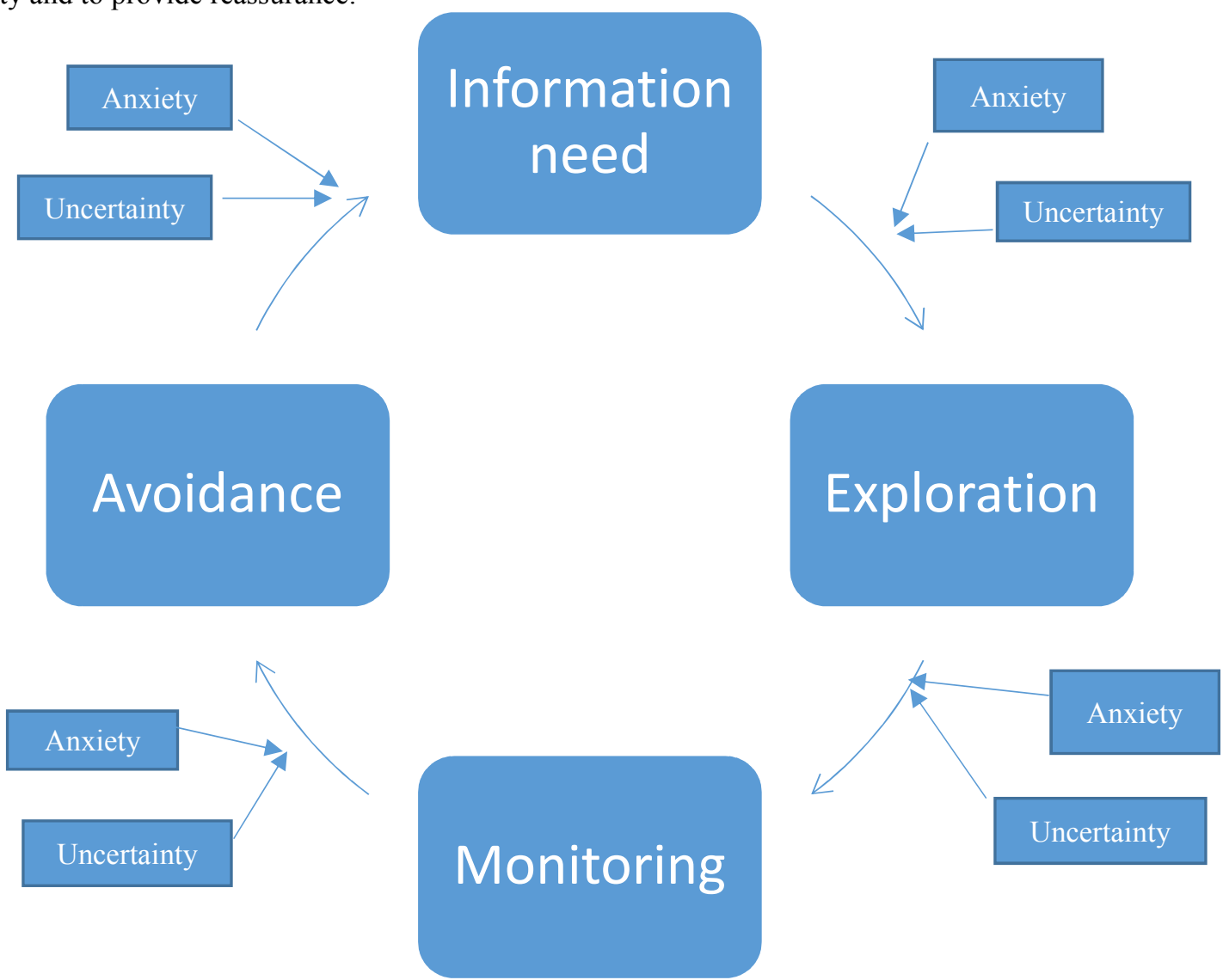

Figure 1. Model of mothers' information behavior during pandemics

\section{Discussion}

\subsection{Information needs}

The findings showed that participants followed information behavior that does not entail any seeking on information, labeling it as avoiding. The notion of avoiding has a long history in psychology, such as in Freud's theories about psychological defenses (Freud, 1923/1962). According to Maslow (1963) "we can seek knowledge in order to reduce anxiety and we can also avoid knowing in order to reduce anxiety". Ignoring or avoiding was well reported in the information behavior literature. According to Ford (2015) avoiding or ignoring information that may upset a person is categorised as information related need, which is needs that have. Implications in the way people interact with information. In other words if interacting with information would cause people any negative feelings or harm they would avoid seeking or reading that information. In health context, avoiding information can occure in many ways, such as avoiding risk information, avoiding healthcare staff or the prognosis (Deline, 2019; Deline \& Kahlor, 2019; Saira et al., 2021) in the context of COVID-19 studies showed that exposure to variety of information on the virus leads to information overload that negatively affects coping mesures (Farooq et al., 2020). Measures of stress and coping can explain such behaviour. in a very interesting study by Alwreikat, Shehata, \& Eldakkar (2021) they found that Arab women had stressful times dealing with the information on COVID-19 because negative feelings as part of the threat appraisal were presence while seeking information on the virus. Such negative feelings triggers a coping behaviour to deal with information on the virus and avoid reading negative information.

\subsection{Exploring}

Exploration is a well-established information seeking behaviour strategy in the literature of information behaviour. Kuhlthau's (2004) model consists of different stages, including Initiation, selection, exploration, formulation, 
collection and presentation. The first three stages are accompanied by uncertainty and doubt most of the times. Kuhlthau focused more on the feelings such as uncertainty and frustration which were associated the need to search for information and solve a problem at the initial stages of the search process, and discussed the ways in which these feelings disappear at the later stages of the search. (Kuhlthau, 2004)

Previous literature came in support results of our data analysis. Mothers showed exploration behavior at the early stages of the pandemic. The exploration behavior is suggested to enhance coping by helping mothers understand the health threat and the associated challenges that it brings. According to Yang (2021) and Ellis (1993) exploration is one of the initial processes involved in information behavior. Sharifirad, et. Al ( 2014) found that individuals tend to seek more information in case of the severity of consequences, such as pandemics.

\subsection{Monitoring}

Monitoring is a directed and passive information seeking, it includes absorb information from the context without engaging in a direct search (Bates, 2002). In support with the findings of our study, van Zuuren \& Wolfs (1991) found that monitoring turned out to be positively related to perceived degree of threat and to unpredictability, and they linked it to avoiding behavior also referred broadly as denial, blunting, or repression, emphasizes individuals choose to divert their attention from the perceived threat

Monitoring found to be a major behavior mothers follow in public health emergencies, and as the results reveal; it is in the purpose to protect their children from getting infected by the virus, by reading more information on the virus spread and updates. According to Martinović (2016) in health information behavior individuals obtain information which is expected to provide aid in dealing with the disease emotionally, which is what the results of this research revealed; mothers acted emotionally and monitored information to aid them in protect their children.

\section{Implications}

The results of this study identifies several implications. First this study bridge the gap between theories of information behavior and the various models available and practice of information behavior during pandemics. Particularly mothers behavior. The results of this research can be used by policymakers and governments in aiding mothers with appropriate support they need in the context of pandemics and public health emergencies, where mothers consider the first psychological source of support to their children in such situations. In general this study contribute to the body of knowledge by providing valuable information on mothers' behavior under pandemics.

\section{Limitations and future research}

This study followed a qualitative approach using semi-structured interviews. The results of this kind of research cannot be generalized as it is based on specific number of interviews. Nevertheless, the results present valuable information to the body of literature, but the researcher suggest using quantitative approaches for future research for more generalizability. The sample of the study considers another limitation as it is based on a group of mothers in a Jordanian elementary school. The researcher also suggests future research to study information behavior of mothers of different age groups, and to study the differences of information behavior of mothers of vaccinated and unvaccinated children.

\section{References}

AH., M. (1963). Further Notes on the Psychology of Being. Journal of Humanistic Psychology., 3(1), 120-135.

Al., F. A. (2020). Impact of online information on self-isolation intention during the COVID-19 pandemic: crosssectional study. J Med Internet Res, 22(5), e19128,

Alwreikat Asma, M. Z., A. S. (2021). Determinants of Facebook use among students and its impact on collaborative learning. Information Development. doi:10.1177/02666669211005819

Alwreikat, Asma, Shehata, A., \& Eldakkar, M. (2021). Arab women feelings while seeking information during COVID-19 pandemic: applying PMT constructs. Online information review https://doi.org/10.1108/OIR-092020-0419

Alwrekat Asma, Rafferty, Pauline \& Foster, Allen. (2015). Cross-language information seeking behaviour English vs Arabic. Library Review, 6/7, 446-467. doi: https://doi.org/10.1108/LR-04-2015-0044

Bates, M. (2002). Toward an integrated model of information seeking and searching. New Review of Information Behaviour Research, 1-15.

Domanović, D. (2020, March 20). Coronavirus disease 2019 (COVID-19) and supply of substances of human origin in the EU/EEA. Retrieved from European Centre for Disease Prevention and Control: https:/www.ecdc.europa.eu/sites/default/files/documents/covid-19-supply-substances-human-origin.pdf

Ellis, D. (1993). Modeling the information-seeking patterns of academic researchers: A grounded theory approach.,. The Library Quarterly, 63(4), 469-486. 1.

Ford, N. (2015). Introduction to information behaviour. London: Facet publishing.

Jan, M. A. (1963). The need to know and the fear of knowing. Gen Psycho, 25-111. doi: 
10.1080/00221309.1963.9920516. PMID:

Kahlor, D. a. (2019). Planned risk information avoidance: A proposed theoretical model. Communication Theory, 3 .

Kuhlthau, C. (2004). Seeking meaning: a process approach to library and information services. Westport, CT: Libraries Unlimited.

Lambert SD, L. C. (2007). Health information seeking behavior. Qual Health Res, 17(8), 1006-1019.

Landry, K. F. (2007). Understanding the information behaviour of the stay-at-home mothers through affect. In Information and Emotion: The Emergent Affective Paradigm in Information Behavior Research and Theor (pp. 2011-234). Information Today, Inc.

Loiselle, S. D. (2017). Health Information-Seeking Behavior. Qualitative Health Research, 17(8), 1006-1019.

M, B. (2017). Influenced by Peers: Facebook as an Information Source for Young People. Social Media + Society. doi:doi: $10.1177 / 2056305117716273$

Martinović, I. \&. (2016). Information Needs and Behaviour of Parents of Children with Autism Spectrum Disorders: Parents. Reports on their Experiences and Perceptions In Proceedings of ISIC, the Information Behaviour Conference,. 1, p. paper isic1609. Zadar, Croatia, : WebCite ${ }^{\circledR}$.

Mary Beth Deline, L. A. (2019). Planned Risk Information Avoidance: A Proposed Theoretical Model. Communication Theory, 29(3), 360-382.

Molteni, M. (2020, March 4). Everything You Need to Know About Coronavirus Vaccines. Retrieved from WIRED.com: https://www.wired.com/story/everything-you-need-to-know-about-coronavirus-vaccines/

Nawrat, A. (2020, Feb 22). Covid-19 outbreak: how misinformation could fuel global panic. Retrieved from Pharmacetucal Technology : https://www.pharmaceutical-technology.com/features/covid-19-outbreak-howmisinformation-could-spark-global-panic/

PierreChauvin, E. R. (2006). Internet use for health information seeking: Lterature reviwe. Rev Epidemiol Sante Publique, 54, 263-275.

S, F. ( 1923/1962 ). ,The ego and the id. New York,: NY: Norton.

SHARIFIRAD, G., \& al, e. (2014). Determination of preventive behaviors for pandemic influenza A/H1N1 based on protection motivation theory among female high school students in Isfahan, Iran. Journal of education and health promotion, 3.

Soroya, S. H. (2021). From information seeking to information avoidance: Understanding the health information behavior during a global health crisis. Information Processing \& Management, 58(2), 102440. doi:https://doi.org/10.1016/j.ipm.2020.102440

van Zuuren, F. J., \& Wolfs, H. M. (1991). Styles of information seeking under threat: Personal and situational aspects of monitoring and blunting. Personality and Individual Differences, 12(2), 141-149.

WHO. (2020, March 2nd). Laboratory testing for coronavirus disease 2019 (COVID-19) in suspected human cases. Retrieved from World Health Orgnization : file://C:/Users/yu/Downloads/WHO-COVID-19-laboratory2020.4-eng.pdf

Yang, J. (2021). Combating pandemic: an exploration of social media users' risk information seeking during the COVID-19 outbreak. Journal of Risk Research, Ahead of print. 